\title{
Results of an Interview Study as Basis for the Categorization of Chemistry Students into Conceptual and Algorithmic Problem Solvers
}

Okanlawon, Ayoade Ejiwale

\begin{abstract}
This work is a report of a micro study carried out on the' effects of higher-order cognitive skills-oriented teaching strategy on the performance of senior secondary school chemistry students in solving stoichiometric problems'. In this study, problem solving category was used as one of the independent variables. This micro study involved 145 senior secondary school chemistry students with average age of 17.6 years, solving Chemistry Paired Algorithmic and Conceptual problems during a speak-aloud session. This exercise was carried out in order to classify them into conceptual and algorithmic problem solvers as well as to expose their misconceptions during problem solving. The results obtained indicated that the proportion of algorithmic problem solvers was greater than those of the conceptual problem solvers. Also, the study revealed that most students were able to solve algorithmic problems but lack the understanding of chemistry necessary for conceptual problems. The implications of this research were discussed in terms of instructional strategies aimed at transforming algorithmic problem solvers into conceptual problem solvers.
\end{abstract}

\section{Introduction}

Normally, any discussion of problem solving has to begin with a definition of the term 'problem' and 'problem solving'. Dewey (1938) stated that a problem is anything that gives rise to doubt and uncertainty. In the view of Hayes (1981) a problem exits when a person perceives a gap between where he or she is and where he or she wants to be but doesn't know how to cross the gap. Within the chemistry context, Weigand and Samberg (2000) define chemistry 
Result of Interview Study as basis for the Categorization Chemistry Students...

problems as story problems that bring together chemistry concepts and mathematical reasoning.

According to Wheatley (1984) problem solving is defined broadly as what one does when one does not know what to do. Problem solving is a process requiring logical and creative thinking (Bybees and Sund, 1990). Mestre, Dunesne, Gerace, Hardiman and Touger (1993) define problem solving as a process which requires the interplay of numerous cognitive factors (e.g. acquisition of a rich base of content knowledge and procedures, organization and retrieval of declarative and procedural knowledge, ability to identify what principle and procedure can be used to solve a problem, ability to execute a solution plan, and ability to evaluate both the solution plan and the answer for accuracy and reasonability). In addition, Cardellini (2006) defined problem as a process in which various reasoning patterns are combined, refined, extended, and invented. It is much more than substituting numbers in well-known and practiced formulae: it deals with creativity, lateral thinking and formal knowledge.

When these definitions are logically applied to a given task, it is easier to determine whether a task is a routine exercise or novel problem. When people first encounter these terms (exercise and problem) they often assume that the different between an exercise and a problem is based on difficulty or complexity. Research findings of Herron (1996) and Bodner (2003) have revealed that problems are neither inherently more difficult nor more complex. The only difference between an exercise and a problem is the element of familiarity. As a rule, extensive practice in problems in a particular area lead to familiarity and this can turn problems into exercises (Zilkovelis and Tsaparlis, 2006). For example, many problems in science can be solved by the application of well-defined procedure (algorithms) (Bodner, 1978) that can turn a tasks that suppose to be problems into algorithmic exercises. Bodner (2003) pointed out that there is a different between the way exercises and problems are worked out; exercises are worked in a linear, forward-chaining, rational manner while problem solving is cyclic, reflective, and can appear irrational. 
Chemistry educators have used various methods to categorize questions as being algorithmic or as requiring conceptual understanding. Conceptual questions have been associated with higher-order cognitive skills (HOCS), and algorithmic questions with lower-order cognitive skills (LOCS) (Zoller, Lubezky, Nakheleh, Tessier and Dori, 1995: Zoller and Tsaparlis, 1997). The literature contains evidence that novice problem solvers in chemistry usually have greater success with solving problems of an algorithmic mode than problems having a more conceptual base (Bunce, 1993; Nakheleh 1993; Gabel \& Bunce, 1994). Niaz and Robinson (1992) concluded that student training in algorithmic-mode problems did not guarantee successful understanding of conceptual problems. According to this study (Niaz and Robinson, 1992), algorithmic and conceptual problems may require different cognitive abilities and problemsolving strategies. Solving conceptual problems demand good conceptual understanding which helps the problem solver to develop a meaningful representation of the problem and to narrow the search for solutions. Various methods (e.g. concept mapping, interview, two-tier multiple-choice diagnostic instruments) are available for determination of students' understanding of concepts., In this study, an in-depth interview was adopted. Interviews are like films. They produce in-depth information about (few) individuals by "the unique interaction between the interviewer and the interviewee" (Kvale, 1996, p. 287). "The research interviewer uses himself as a research instrument" (Kvale, 1996, p.125). In doing so, new variables are introduced. As a result different interviewers may come up with different interviews. Hence, this study is unique when compared to other studies that are based on problem solving category.

\section{Algorithmic versus Conceptual Approach}

Algorithmic approach (i.e. quantitative mathematical-based approach) is simply described as mechanized habits of response to problem (Meija and Bisenieks, 2004). Also, Suits (2001) referred to it as a problem solving process which requires substitution of numbers in a prescribed scheme (i.e. formula or equation). Since algorithmic 
approach demands the use of a memorize formula and manipulation of that formula based on the problem goal(s), it is susceptible to mathematical formula (algorithmic) setup errors. This error occurs when a formula or equation is used as the algorithm to solve a problem requiring the correct rearrangement for the calculation of the unknown. For example, a problem solver wishing to determine the amount (in mole) of a solute, given the molar concentration and volume of solution, may end up computing the amount (in mole)

$$
=\mathrm{C} / \mathrm{V} \text { or } \mathrm{V} / \mathrm{C} \text {. }
$$

Another identified weakness of algorithmic techniques is that they are not sufficient for solving a problem completely; however, algorithms are useful and necessary for solving several important parts of a problem. For example, Meija and Bisenieks (2004) clearly expressed the limitation of this approach by stating that the problem-solving stages requiring mathematical skills are (i) implementing the proposed strategy and (ii) evaluating the result obtained while it is irrelevant in understanding the problem and in developing the solution strategy.

Rote, algorithmic-type teaching and learning hinder chemistry students' development of conceptual understanding and higher-level thinking skills (Robinson, 2003). On many occasions during learning process, learners store information in a compartmentalized way and are unable to transfer what is learned in one context or setting to another context or setting and hence learning is situated in the original learning context (Reid and Yang, 2002; Novak, 2002). This further prevents them from coming up with a well-reasoned solution to the quantitative problem at hand (Gabel, 1998).

Qualitative (conceptual) approach to problem solving is an effective technique by which experts integrate concepts and procedure to solve problem. This approach is considered to be functional for students and teachers in identifying misconceptions and deficiencies in the underlying conceptual base (Ardac, 2002). The use of conceptcentered approach results in a solution that linked quantitative 
problem-solving strategies to an understanding of the underlying chemical principles. In Nigeria, teachers in the senior secondary schools and the examination bodies (West African Examinations Council) encourage the use of algorithmic formulae for solving chemical problems rather than promoting the use of reasoning combined with an understanding of the concepts underlying the problems when solving chemistry problem. For instance, the above mentioned examination bodies allow the use of the equation $\mathrm{C}_{1} \mathrm{~V}_{1}=$ $\mathrm{C}_{2} \mathrm{~V}_{2}$ (where $\mathrm{C}$ represents molar concentration and $\mathrm{V}$ represents solution volume) to handle calculations in volumentric analysis. Such algorithm, which may seem helpful at first glance, actually promote an approach that hinders meaningful learning and true understanding.

The problem solving approach adopted by a problem solver and problem solving behaviour exhibited while engaging in problemsolving process will determine the category to which a problem solver would belong to. For instance, the problem solvers who approach the problem given below using method I would be classified as algorithm problem solvers while those that follow the solution pathway labeled as method II would be grouped as conceptual problem solvers.

\section{Problem}

$3.0 \mathrm{~g}$ of an impure sample of sodium trioxocarbonate (iv) was dissolved in distilled water and the solution was made up to $250 \mathrm{~cm}^{3}$. $25 \mathrm{~cm}^{3}$ portion of the solution was on titration, completely neutralized with $20.40 \mathrm{~cm}^{3}$ of hydrochloric acid containing 0.2 mole of acid per $\mathrm{dm}^{3}$. Calculate the percentage purity of the sample of sodium trioxocarbonate (iv). The equation for the reaction is:

$$
\begin{aligned}
& 2 \mathrm{HCI}_{(\mathrm{aq})}+\mathrm{Na}_{2} \mathrm{CO}_{3(\mathrm{aq})} \longrightarrow 2 \mathrm{Na} t \mathrm{Cl}_{(\mathrm{aq})}+\mathrm{CO}_{2(\mathrm{~g})}+\mathrm{H}_{2} \mathrm{O}_{(1)} \\
& {[H=1, C=12, \mathrm{O}=16, \mathrm{Na}=23]}
\end{aligned}
$$

Solution: Method I (Algorithmic technique)

$$
2 \mathrm{HCl}_{(\mathrm{aq})}+\mathrm{Na}_{2} \mathrm{CO}_{3(\mathrm{aq})} \longrightarrow 2 \mathrm{NaCl}_{(\mathrm{aq})}+\mathrm{CO}_{2(\mathrm{~g})}+\mathrm{H}_{2} \mathrm{O}_{(1)}
$$


Result of Interview Study as basis for the Categorization Chemistry Students...

Mole ratio of acid to base $=2: 1$

$\frac{C_{a} V_{a}}{C_{b} V_{b}}=\frac{n_{a}}{n_{b}} \quad ; \quad \frac{0.2 \times 20.40}{C_{b} \times 25}=\frac{2}{1}$

$50 \mathrm{C}_{\mathrm{b}}=20.40 \times 0.2 ; \mathrm{C}_{\mathrm{b}}=\underline{20.40 \times 0.2}=0.082 \mathrm{~mol} . \mathrm{dm}^{-3} 50$

Molar mass of $\mathrm{Na}_{2} \mathrm{CO}_{3}=106 \mathrm{~g} \cdot \mathrm{mol}^{-1}$

Mass concentration = Molar concentration $x$ Molar mass

$$
\begin{aligned}
& =\quad \frac{0.082 \underline{\mathrm{mol}}}{\mathrm{dm}^{3}} \times \frac{106 \mathrm{~g}}{\mathrm{~mol}} \\
& =8.69 \mathrm{~g} / \mathrm{dm}^{3}
\end{aligned}
$$

$250 \mathrm{~cm}^{3}$ solution contain $3.0 \mathrm{~g}$ of impure $\mathrm{Na}_{2} \mathrm{CO}_{3}$

$1000 \mathrm{~cm}^{3}$ solution contain $1000 \times 3.0 \mathrm{~g}$ of impure $\mathrm{Na}_{2} \mathrm{CO}_{3}$

250

$$
=12 \mathrm{~g}
$$

$\%$ Purity $=\frac{8.69}{12} \times 100=72.0 \%$

Solution: Method II (concept-based technique)

$1000 \mathrm{~cm}^{3}$ solution contain 0.2 mole of $\mathrm{HCl}$

$20.4 \mathrm{~cm}^{3}$ solution contain $20.40 \times 0.2$ mole $\mathrm{HCl}$

1000 
From the chemical equation, 2 moles $\mathrm{HCl}$ react with 1 mole $\mathrm{Na}_{2} \mathrm{CO}_{3}$

Number of moles $\mathrm{Na}_{2} \mathrm{CO}_{3}$ used

$$
=\frac{20.40}{1000} \times 0.2 \times \frac{1}{2}
$$

$$
=\quad 2.04 \times 10^{-3} \text { mole. }
$$

$25 \mathrm{~cm}^{3}$ solution contain $2.04 \times 10^{-3}$ mole $\mathrm{Na}_{2} \mathrm{CO}_{3}$

$$
\begin{aligned}
& 250 \mathrm{~cm}^{3} \text { solution contain } \frac{2.04}{1000} \times 10 \text { mole } \mathrm{Na}_{2} \mathrm{CO}_{3} \\
& 250 \mathrm{~cm}^{3} \text { solution contain } \frac{2.04}{1000} \times 10 \times 106 \mathrm{~g} \mathrm{Na}_{2} \mathrm{CO}_{3} \\
& =\quad 2.16 \mathrm{~g} \mathrm{Na}_{2} \mathrm{CO}_{3} \\
& \% \quad \text { Purity }=\frac{2.16}{3.0} \times 100=72 \%
\end{aligned}
$$

Another way of classifying students into algorithmic and conceptual problem solver was provided in the previous studies on problem categorization. When asked to categorize problems into groups, with the problems in each group related by the approach that would be used to solve them, conceptual problem solvers rely on the problems' deep structure (i.e. principles and concepts that could be applied to solve the problem) as the classification criterion (Chi, Feltovich, and Glaser 1981; Hardiman, Dufresne, and Mestre, 1989; Schoenfeld and Herrmann, 1982). In contrast, algorithmic problem solvers rely on the problems' surface features (i.e., objects and terminology described in the problems). 


\section{Differences between Algorithmic and Conceptual Problem Solvers} Research on problem solving consistently provides evidence for the importance of conceptual knowledge base in explaining problem solving performance (Bunce and Heikkinen, 1986; Nurrenbern and Pickering, 1987; Pickering, 1990). With appropriate integration of related ideas and elimination of irrelevant information, experts are believed to possess a rich, organized, coherent, and globally consistent knowledge base, which enables them to deal effectively with both familiar and unfamiliar problems within their discipline domain (Chi, Feltovich and Glaser, 1981). On the other hand, novices possess a highly fragmented and incoherent knowledge base with several inconsistencies (Chi, Glaser and Rees, 1982; diSeassa, 1993; Hammer, 1994). Novices also tend to use their knowledge in a linear fashion in which each inference follows from another statement in only one way, whereas experts tend to use a network structure in which inferences can be reached along different pathways (Larkin, 1983). More differences between conceptual and algorithmic learners (i.e. experts and novices) are believed to abound. According to Glaser and Chi 1988) these differences include the fact that experts:

1. are fast and accurate at solving problems within their domain because with practice, many skills have become automated. This frees up cognitive resources for processing other aspects of the task.

2. represent problems at a deeper level than novices do, because of the former superior conceptual understanding.

3. spend a great deal of time analyzing and representing a problem before they start solving it. This provides them with a cognitive representation which further allows them to infer the relevant relations and constraints. Novices do not follow such procedures.

4. have strong self-monitoring skills. 
On the other hand, Herron and Greenbowe (1986) stressed some of the ways novice students approach problem solving that are differ from experts as follows:

1. Often focus on inappropriate aspects of a problem.

2. May change the problem representation during problem solving.

3. Sometimes apply procedures rigidly and inappropriately.

4. Let their beliefs guide their approach to problem solving.

5. Often systematically distort the problem to be consistent with prior knowledge.

6. Have difficulty in breaking down a complex problem into sub-problems.

7. Have difficulty seeing the explicit steps taken by experts to solve problems.

8. Misunderstand or change the goal of the problem.

9. Do not fully understand the conditions placed on a problem.

10. May include unnecessary assumptions.

11. May not spend much time on analyzing the problem.

12. Have difficulty seeing the problem as a "whole".

13. May not spend much time on verification: students who have no confidence in their problem solving ability often see little point in spending additional time checking their work.

Novice problem-solving generally depends on the use of non-formal modes of concept interpretation in which already existing standard cases are automatically triggered from long term memory. Automatically processing, although quick and effortless, has serious drawbacks. Since there is little or no reference to the underlying conceptual framework, inconsistencies and erroneous conceptions in 
the knowledge base are usually overlooked and may not be detected even during the evaluation practices (Krulik and Rudrick, 1980; Reif, 1983; Niaz, 1995). Accumulated evidence shows that it is possible to produce right answers to chemistry problems without really understanding much of the chemistry involved and that the ability to solve numerical problems in chemistry does not necessarily demonstrate an understanding at the molecular level (Herron and Greenbowe, 1986; Bunce, Gabel and Samuel, 1991; Niaz and Robinson, 1992; Nakhleh, 1993; Nakhleh and Mitchell, 1993).

Novice problem-solvers consistently show greater success in solving algorithmic problems than conceptual problem solvers (Sawrey, 1990; Mason, Shell, and Crawley, 1997). Unfortunately however, strict reliance on algorithmic techniques results in problem-solving difficulties when existing algorithms and standard cases are either not significant to deal with possible situations or when they are retrieved indiscriminately even though they are not applicable (Chi, 2001; Zoller, 2002). Conceptual difficulties become more evident in attempts to solve problems that require construction of a novel algorithm (Ardac, 2002).

\section{Purpose of the Study}

In this study, problem-solving behaviours verbalized by the chemistry students when solving problems, Chemistry Paired Algorithmic and Conceptual Test (CHEMPACT) were explored. The objectives of this study were to: (i) identify students belonging to the algorithmic and conceptual problem solvers categories (ii) document the conceptions that the senior secondary school (SS2) students express when solving problems relating to the prerequisite knowledge skills for learning stoichiometry. From a pedagogical perspective, it is assume that a better understanding of problem solving categories and students' conceptions of chemistry concepts will provide important insights for developing more appropriate curriculum materials and instructional strategies. 


\section{Methodology}

One hundred and forty-five students from four randomly senior secondary schools in Ogbomoso metropolis participated in the written test as well as in an audiotaped interview which took place during the lunch period and after classroom work. The students consisted of fifty-two females $(35.9 \%)$ and ninety-three males $(64.1 \%)$ with average age of 17.6years. Those students had been taught the prerequisite knowledge skills required for solving stoichiometric problems in their various schools.

The only instrument used in this study is labelled Chemistry Paired Algorithmic and Conceptual Test (CHEMPACT). This test consists of four groups of paired algorithmic and conceptual questions on atomic structure, chemical formula and equation, moles concept, states of matter and gas law (Appendix I). These topics were chosen because of their frequency of occurrence in the Senior School Certificate Examination (SSCE) conducted by the West African Examinations Council (WAEC) and the National Examinations Council (NECO).

\section{Procedure}

A paper-and-pencil test (CHEMPACT, ) consisting of four paired questions on prerequisite knowledge skills for solving stoichiometric problems was administered to the students. After taking the test, subjects were engaged in a speak-aloud session using the same test. During this phase, students were asked to solve the four paired questions aloud. Speak - aloud sessions were conducted using the guidelines developed by Hartman (1996). Speak - aloud sessions were considered by science educators (Newell \& Simon, 1972; Anderson, 1986) to be helpful for students and teachers in identifying misconceptions and deficiencies in the underlying conceptual base. The performances of students in both the written and verbal responses to the CHEMPACT were used to categorize students into conceptual and algorithmic problem solvers. Correct written answers and explanations were awarded 1 mark for a possible total of 8marks. Incorrect answers and explanations received a score of zero, 0 . To be 
classified as a algorithmic problem solver, a student must have correctly solved three or four of the algorithmic and two or less conceptual - mode problems. On the other hand, to qualify as a member of the conceptual problem solvers' group a student would have correctly solved three or four of the conceptual and four or less algorithmic - mode problems. Failure to meet up with the criteria used in categorizing students as either conceptual or algorithmic problem solvers, students would be considered as lacking both the mathematical and conceptualization skills. Frequency counts and percentages were used in analyzing students' responses to the CHEMPACT.

\section{Results and Interpretation}

Sample Responses of Students to CHEMPACT

Below are the illustrative excerpts that enabled the investigator to classify students in the experimental and control groups as algorithmic and conceptual problem solvers. In the excerpts below, $\mathrm{R}$ stands for the researcher and S stands for the student.

\section{Sample responses for Algorithmic problem solvers}

$\mathrm{R}$ : What do you think is the correct answer to question 1(a)?

S1: It is not easy to answer instantly, let me think on it. [Pause for some minutes]

R: $\quad$ You are allowed to do so.

S1: I think its option A. That is

R: $\quad$ Okay. Go ahead and explain your answer.

$\mathrm{S} 1$ : It is because of the fact that all elements listed as options are metals except chlorine which is a non-metal. The chemical behaviour of chlorine is similar to that of sodium, this makes it possible for the two elements to react together forming a covalent bond; whereas metals cannot react with metals.

$\mathrm{R}: \quad$ Is that all you need to say?

S1: I think my explanations are just $\mathrm{OK}$.

R: Alright, thank you. 
Comment: Questions 1(a) and 1(b) of the CHEMPACT were not equivalent in terms of the level of cognitive skill required on the part of students. The reasoning of students S1 appears to be based on the misconception that since a chlorine atom can form a covalent bond with a sodium atom, and then both elements have similar chemical properties. Consequently, student S1 lacks deep understanding of atomic structure which could be used in answering question 1(a).

R: $\quad$ Here you have a question to answer. The question is 1(b). What are the numbers of protons and neutrons present in the nucleus of isotope ${ }_{92}^{238} \mathrm{~B}$ ?

S2: [The boy looked at the question paper] Oh yes, we've been taught in SS1 that the subscripts in this symbol, ${ }_{92}^{238} \mathrm{~B}$ is the proton number. Hence, its nucleus contains 92 protons.

R: $\quad$ You have answered a part of the question. What about the number of neutrons?

S2: We have been taught how to do this as well. To determine the number of neutrons, I need to use a formula ... mass number is the addition of proton number and neutron number. If I subtract 92, that is proton number from mass number (238), my result is 146 which is the number of neutrons.

R: $\quad$ So, you have calculated the number of neutrons to be 146 .

S2: $\quad$ Yes, isotope B contains 146 neutrons in its nucleus.

Comment: Student S2 recognized that the subscript in the symbol ${ }_{92}^{238} \mathrm{~B}$ represents the number of protons present in the isotope. He answered the first part of the question correctly. When asked to calculate the number of neutrons, students S2 quickly recalled that by subtracting the atomic number (i.e., number of protons contained in 
the atom's nucleus) from the mass number, the number of neutrons can be easily determined.

R: $\quad$ Let's talk about question 4(b) (Appendix III). Please, speak aloud while you go about solving it.

S3: Let me first think on the law to be applied because this is a problem on gas law.

R: $\quad$ OK. Go ahead.

S3: In this case, I need to use Charles' law, $\mathrm{V}_{1} / \mathrm{T}_{1}=\mathrm{V}_{2} / \mathrm{T}_{2}$. The value of $V_{1}$ is $92 \mathrm{~cm}^{3}, T_{1}=276 \mathrm{k}$ and $T_{2}$ is $291 \mathrm{k}$. The value of the final volume, $V_{2}$ can be calculated by making $V_{2}$ the subject of the formula.

R: How?

S3: By rearranging, $\mathrm{V}_{2}=\mathrm{V}_{1} \mathrm{~T}_{2} / \mathrm{T}_{1}$ and substituting $276 \mathrm{k}, 291 \mathrm{k}$ and $92 \mathrm{~cm}^{3}$ for $T_{1}, T_{2}$ and $V_{1}$ respectively. After that the value of $\mathrm{V}_{2}$ can be calculated.

R: Just that?

S3: Yes.

Comment: Question 4(b) is based solely on knowing and hence deep thinking is irrelevant in answering it. The foregoing excerpt is an illustration of a student who can recall and apply learned rule correctly. From experience, he knew that by substituting given values into the expression, $V_{2}=V_{1} T_{2} / T_{1}$, the value of the final volume can be computed.

R: Judging from your answer script, option A is the correction answer. Why do you think it is correct?

S4: It is a simple question. I am sure option A is right.

R: $\quad$ Could you explain how you have arrived at it. 
S4: Oh yes (laughs). The symbols and charges of sodium and sulphur are provided in the problem statement. This makes the question easier. Simply, by writing the symbols and interchanging the charges, the formula $\mathrm{Na}_{2} \mathrm{~S}$ is obtained.

R: $\quad$ Alright thank you. But I still need to ask some questions relating to question 2 (b).

Can I go ahead?

S4: Ok, Sir.

R: Now listen carefully to my questions. Firstly, why is sodium ion carries a single positive charge and not double?

S4: $\quad$ Because it is a group I element like potassium.

R: I realized that they both belong to group $\mathrm{I}$ in the Periodic Table of elements but why do they classified as group I elements?

S4: I don't know. But may be both are reactive metals.

R: Ok. Let me ask another question. Could you write the ground-state electronic configurations of sodium and sulphur using the $\mathrm{s}, \mathrm{p}$, d notation.

S4: (Writes)

${ }_{11} \mathrm{Na}=1 \mathrm{~s}^{2} 2 \mathrm{~s}^{2} 2 \mathrm{p}^{6} 3 \mathrm{~s}^{1} ; \quad{ }_{16} \mathrm{~S}=1 \mathrm{~s}^{2} 2 \mathrm{~s}^{2} 2 \mathrm{p}^{6} 3 \mathrm{~s}^{2} 3 \mathrm{p}^{4}$

$\mathrm{R}$ : Using their electronic configurations as written by you, deduce their respective valences.

S4: $\quad$ For sodium is one but for sulphur it is four.

$\mathrm{R}$ : $\quad$ Are you sure of what you are saying?

S4: Yes. I am correct.

R: Now, using your knowledge of electronic configuration describe what happens during chemical combination between sodium and sulphur atoms.

S4: During bond formation between sodium and sulphur atoms, sodium atom transfers one electron to sulphur atom while sulphur atom in turn transfers two electrons to sodium. So, there was exchange of electrons.

R: Thank you. 
Comment: Student 4 (S4) was able to apply the first two steps of writing the correct formulae of simple inorganic compounds in selecting the correct option (i.e., $\mathrm{Na}_{2} \mathrm{~S}$ ). These steps are (1) place valence in Arabic numerals under the element or radical and (2) crisscross these numerals to form subscripts. Surprisingly, she was unable to explain what happens during bond formation between the two atoms (i.e., sodium and sulphur). She lacked understanding of the underlying chemical principles which resulted in the formation of $\mathrm{Na}_{2} \mathrm{~S}$. Also, she held misconceptions concerning valency of elements and chemical bonding (e.g ionic bonding). This is revealed in the foregoing excerpt in which student 4 considered ionic bonding to be involving exchange of electrons between the two participating atoms.

\section{Sample Response for Conceptual Problem Solvers}

$\mathrm{R}$ : Looking at your answer sheet, you chose option $\mathrm{C}$ as your correct answer to question 3(b). Will you please explain what you did before arriving at 0.25 mole?

S5: I wrote the formula, $\mathrm{n}=\mathrm{m} / \mathrm{M}$, then I calculated the molar mass of $\mathrm{Al}_{2}\left(\mathrm{SO}_{4}\right)_{3}$ to be $342 \mathrm{~g} \mathrm{~mol}^{-1}$. I have $85.5 \mathrm{~g}$ (given in the question) as the mass of $\mathrm{Al}_{2}\left(\mathrm{SO}_{4}\right)_{3}$ which is substituted for $\mathrm{m}$ while $342 \mathrm{gmol}^{-1}$, the molar mass is substituted for M. Thereafter, I divided $85.5 \mathrm{~g}$ by 342 so as to obtain the number of mole.

R: $\quad$ Do you think your procedure for calculating the number of moles is correct?

S5: Yes, I'm sure.

R: $\quad$ Please, could you explain the statement that the molar mass of $\mathrm{Al}_{2}\left(\mathrm{SO}_{4}\right)_{3}$ is $342 \mathrm{gmol}^{-1}$ ?

S5: [Pause for some minutes]. This statement means, 1 mole of $\mathrm{Al}_{2}\left(\mathrm{SO}_{4}\right)_{3}$ has a mass of $342 \mathrm{~g}$.

R: $\quad$ You are correct. Now, listen to me. If you have $85.5 \mathrm{~g}$ of $\mathrm{Al}_{2}$ $\left(\mathrm{SO}_{4}\right)_{3}$ in a crucible, what is the numbers of moles present in it?

S5: Well, since $342 \mathrm{~g}$ of $\mathrm{Al}_{2}\left(\mathrm{SO}_{4}\right)_{3}$ contain 1 mole of $\mathrm{Al}_{2}\left(\mathrm{SO}_{4}\right)_{3}$, $85.5 \mathrm{~g}$ of $\mathrm{Al}_{2}\left(\mathrm{SO}_{4}\right)_{3}$ will contain $85.5 \mathrm{~g}$ divided by 342 and the 
answer will be 0.25 mole. This shows that the number of moles is equal to mass given divided by the molar mass.

R: $\quad$ Thank you.

Comment: Question 3(b) is a algorithmic question which can be solved by applying algorithm technique. This technique involves substitution of numbers in a prescribed scheme. The foregoing excerpt is an illustration of a student who could not only recall and apply learned formula but also understood the underlying structure upon which the formula, $n=m / M$ is based.

$\mathrm{R}: \quad$ How many moles of ions are there per mole of $\mathrm{Al}_{2}\left(\mathrm{SO}_{4}\right)_{3}$ ?

S6: [Holding the question paper]. Five that is option $\mathrm{C}$

R: $\quad$ Correct. Now let's go back to the question again. Okay, what do you think would happen if few grams of $\mathrm{Al}_{2}\left(\mathrm{SO}_{4}\right)_{3}$ are dropped in to a beaker containing water?

S6: $\quad \mathrm{Al}_{2}\left(\mathrm{SO}_{4}\right)_{3}$ dissolves in water to form solution

$\mathrm{R}$ : Well, is there any ion present in the solution formed?

S6: [The girl shook her head and shrugged her shoulders as well]. There are ions contained in $\mathrm{Al}_{2}\left(\mathrm{SO}_{4}\right)_{3}$ solution.

$\mathrm{R}$ : What are these ions?

S6: [She brought out a sheet of paper and wrote equation for the ionization of $\left.\mathrm{Al}_{2}\left(\mathrm{SO}_{4}\right)_{3}\right]$. The ions are aluminium ions and tetraoxosulphate (VI) ions.

R: Okay, you are right. But could you explain your answer further?

S6: Oh yes, $\mathrm{Al}_{2}\left(\mathrm{SO}_{4}\right)_{3}$ is an ionic compound. It is also a soluble salt. It ionizes in water forming $\mathrm{Al}^{3+}$ and $\mathrm{SO}_{4}{ }^{2-}$. The aluminium ion is a aluminium atom that has lost three electrons and is therefore positively charged, while a tetraoxosulphate (VI) ion is a group of atoms that has gained two electrons and therefore is negatively charged.

R: $\quad$ Could you tell me the number of moles of each ion formed?

S6: [The girl appeared puzzled for some minutes]. I know the answers [laughs]. Two moles of $\mathrm{SO}_{4}^{2-}$ and three moles of $\mathrm{Al}^{3+}$ 
R: Now, what is the total number of ions formed per mole of $\mathrm{Al}_{2}\left(\mathrm{SO}_{4}\right)_{3}$ ?

S6: $\quad$ It is 5 moles.

Comments: The responses of student S6 indicate that she possessed good conceptual understanding of ionization of salts in water. In answering question 3(a), application of memorized algorithms is not helpful because it is a conceptually - oriented question. Interestingly, she was able to identify $\mathrm{Al}_{2}\left(\mathrm{SO}_{4}\right)_{3}$ as ionic salt in which one mole of it ionizes in water forming 2 moles of $\mathrm{SO}_{4}^{2-}$ and 3 moles of $\mathrm{Al}^{3+}$.

R: Let us have a look at question 2(a). It appears that two elements, $\mathrm{P}$ and $\mathrm{Q}$ with atomic number 11 and 8 respectively combined together to form compound $\mathrm{P}_{\mathrm{x}} \mathrm{Q}_{\mathrm{y}}$. Then, what are the values of $\mathrm{x}$ and $\mathrm{y}$ ?

S7: $\quad 2$ and 1

R: Well, you selected option E. But why?

S7: $\quad$ Many things are to be explained.

R: $\quad$ Go ahead with your explanation

S7: $\quad$ Knowing that the atomic numbers of $\mathrm{P}$ and $\mathrm{Q}$ are 11 and 8 respectively, then their valencies are 1 and 2 respectively. Using atomic number.......... [Interrupted by researcher]

R: What do you mean by saying "their valencies are 1 and 2 respectively"

S7: The valency of element $P$ is 1 and that of element $Q$ is 2 . The formula of the compound formed by $\mathrm{P}$ and $\mathrm{Q}$ is $\mathrm{P}_{2} \mathrm{Q}$. That is, the valency number for $\mathrm{P}$ is written as a subscript to $\mathrm{Q}$ and the valency number for $\mathrm{Q}$ is written as a subscript to $\mathrm{P}$.

R: $\quad$ You have not answered my question. You have explained the rule applied in writing formula. What do you really mean by valency?

S7: Valency. Valency. [Pause]. The valency of an element is defined as the number of hydrogen atoms which one atom of the element will combine with or will replace. 
R: Having defined valency, then relate your definition to the determination of valencies of $\mathrm{P}$ and $\mathrm{Q}$.

S7: Okay. Mmm........ the valency of $\mathrm{P}$ is 1 as it combines with one hydrogen atom while $\mathrm{Q}$ combines with two hydrogen atoms; hence its valency is 2 .

R: $\quad$ Why are the two elements having different valencies?

S7: $\quad$ The reason is quite obvious. $\mathrm{P}$ and $\mathrm{Q}$ have different atomic numbers; hence they have different electronic configurations.

R: Could you write the electronic configurations of both elements?

S7: $\quad$ Oh yes. Electronic configurations of $\mathrm{P}$ and $\mathrm{Q}$ can be written as $(2,8,1)$ and $(2,6)$ respectively.

$\mathrm{R}$ : Is electronic configuration useful in determining valency?

S7: It is useful. For instance, an atom of $\mathrm{P}$ can lose one electron from its outermost shell, hence its valency is one. On the other hand, an atom of $\mathrm{Q}$ can accept two electrons that is passed over to its outer electron shell from another atom. Since an atom of $\mathrm{Q}$ can accept two electrons to attain noble configuration then its valency is two.

R: Thank you.

Comment: The foregoing excerpt is illustrative of students who had the relevant knowledge of atomic structure and valency. Student S7 used his understanding of electronic configurations of the two elements, $\mathrm{P}$ and $\mathrm{Q}$ in determining their valencies. Hence, he was able to select the correct option.

Table 1 presents a summary of the frequency distribution of students based on their performances on CHEMPACT. In School I, a total of 18 students were classified as conceptual problem solvers. In School II, a total of 17 (out of 40) were algorithmic problem solvers while 13 of them were classified as conceptual problem solvers. In School III, a total of 20 (out of 38) students were algorithmic problem solvers while 13 students were grouped as conceptual problem solvers. In School IV, a total of 11 (out of 32) students were algorithmic problem 
solvers while 9 students were classified as conceptual problem solvers. The results obtained showed that there are more algorithmic problem solvers than conceptual problem solvers in the four groups.

\section{Discussion}

The proportion of algorithmic problem solvers is greater than those of the conceptual problem solvers among the second year chemistry student (Table 1). This result indicates that a fairly large number of chemistry students $(45.5 \%)$ are algorithmic problem solvers. That is, a reasonable proportion of students lacked understanding of concepts in chemistry. A major reason for this observation could be that the students were taught traditionally in their various schools. In a traditional chemistry class, the predominant method of delivering instruction is lecture. This instruction gives attention to the sequence of steps used to solve the problem rather than the underlying principles upon which the problems is based. Students were then assigned practice problems analogous to the worked-out examples with the assumption that such practice will result in an improved performance. Mostly, they work on the problems individually and alter submitting their work for assessment. Both research and experience suggest that this method of instruction is not adequate and students that are subjected this kind of treatment may be able to solve problems using their mathematical ability alone and not necessarily understand the underlying chemistry concept. Student exhibiting such characteristic usually develop non-standard thinking approaches which is not applicable in all problem solving process.

Another possible reason for the result obtained is that in traditional setting, teachers do not link errors on students' solution to misconceptions. Simply, they based their grading on the correct answers and in many cases errors could serve as evidence of misconceptions. Such grading system breed high population of algorithmic problem solvers because solutions based on algorithmic technique fail to reveal students' erroneous conceptions in their knowledge base. For instance, the responses of student 4 (S4) to question 2(b) revealed that she was able to solve the problem correctly 
by selecting the correct option, however, she held misconceptions concerning chemical bonding.

\section{Conclusion}

Many times rote memorization is rewarded, rather than critical thinking and reflection. Isolated facts are valued over integrated scientific understanding, where concepts in subsystems are related to a larger system and other systems. Actively constructing conceptual knowledge is not encouraged, and many topics are re-taught in isolation and with needless detail. No wander that chemistry students tend to memorize algorithms rather than learning the underlying concepts. To solve problem through understanding rather than by rote learning or using algorithmic techniques, students must possess a well connected knowledge base. This implies that to be a good problem solver one must have a coherent, structured and high quality knowledgeable conception of the problem.

A major purpose of science education is to have students construct a deep conceptual understanding of any scientific topic studied. This is necessary because problem solving requires possession of better conceptual understanding which allows experts to quickly recognize meaningful patterns and conceptualize problems at a deep level. Problem solving in science is based on an understanding of the concepts and the rules interrelating them; that is, only a meaningful understand (Ausubel, 1978) of concepts and clear conceptual connections between them can lead to the desired behaviour in problem solving.

Since problem solving is complex and problems take on a myriad of forms, chemistry teachers must be fully aware that instructional strategies which both enhance the quality of the knowledge base in problem solving should be of great benefits to their students. Essentially, any activity that increases conceptual knowledge, encourages persistence, increases motivation, and helps students to see connections among ideas. To reflect on and check what was done, 
Result of Interview Study as basis for the Categorization Chemistry Students...

to consider alternative interpretations and to try different strategies is likely to improve problem solving.

\section{References}

Anderson, M. A. (1986). "Exploration of Individual Differences in ProblemSolving Processes/Strategies Using Verbal Reports: Protocol Analysis." A Paper Presented at the Meeting of the American Educational Research Association, San Francisco, CA.

Ardac, D. (2002). "Solving Quantum Number Problems: An Examination of Novice Performance in Terms of Conceptual Base Requirements." Journal of Chemical Education, 79 (4), 510 - 513.

Ansubel, D. P. (1978). "In Defence Of Advance Organizers: A Reply to the Critics." Review of Educational Research, 48, 251 - 257.

Bodner, G. (1987). "Role of Algorithms in Teaching Problem Solving." Journal of Chemical Education, 64, 513 - 514.

Bodner, G. (2003). "Problem Solving: The Difference Between What We Do and What We Tell Students to Do." University Chemistry Education, 7, 37 - 45.

Bunce, D. M. (1993). "Introduction.” Journal of Chemical Education, 70(3), $179-180$.

Bunce, D. M., Gabel, D. L. \& Samuel, J. V. (1991). "Enhancing Chemistry Problem-Solving Achievement Using Problem Categorization”, Journal of Research in Science Teaching, 28, 505 - 521.

Bunce, D. M. \& Heikkinen, H. (1986). "The Effects of an Explicit ProblemSolving Approach on Mathematical Chemistry Achievement", Journal of Research in Science Teaching, 23, $11-20$.

Bybee, R. W., \& Sund, R. B. (1990). Piaget for Educators. Second Edition. Waveland Press, Inc.

Cardellini, L. (2006). "Fostering Creative Problem Solving in Chemistry through Group Work", Chemistry Education Research and Practice, $7(2), 131-140$.

Chiu, M. H. (2001). “Algorithmic Problem Solving and Conceptual Understanding of Chemistry by Students at a Local High School in Taiwan." Proceedings of National Science Council, ROC (D), 11(1), $20-38$. 
Chi, M.T.H., Feltovich, P. J., \& Glasser, R. (1981). "Categorization and Representation of Physics Problems by Experts and Novices". Cognitive Science, 5, 121 - 152.

Chi, M.T.H., Glaser, K. \& Rees, E. (1982). Advances in the Psychology of Human Intelligence. Hilsdale, NJ. Lawrence Erlbaum Associates.

Dewey, J. (1938). Experience and Education. New York: Macmillan. diSessa, A. A. (1993). "Toward an Epistemology of Physics." Cognition and Instruction, 5, 100 - 112.

Gabel, D. (1993). "Use of the Particle Nature of Matter in Developing Conceptual Understanding." Journal of Chemical Education, 70, $193-194$.

Gabel, D. L. \& Bunce, D. M. (1994). "Research on Problem Solving. In D. Gabel (ed.), Handbook of Research on Science Teaching and Learning, pp. 301 - 326. New York: Mac Millan.

Glaser, R., \& Chin, M.T.H. (1988). Overview. In M.T.H. Chi, R. Glaser, \& M. J., Farr (Eds.), The Nature of Expertise (pp. xv - xxviii). Hillsdale, N. J.: Erlbanum.

Hardiman, P. T., Dufresne, R., \& Mestre, J. P. (1989). "The Relationship between Problem Categorization and Problem Solving among Experts and Novices." Memory and Cognition, 17, 627 - 638.

Hammer, D. (1994). "Epistemological Beliefs in Introductory Physics". Cognition and Instruction, 12, $151-183$.

Hayes, J. R. (1981). The Complete Problem Solver. Philadelphia: The Franklin Institute Press.

Herron, J. D. (1996). The Chemistry Classroom: Formulas For Successful Teaching. Washington, DC: American Chemistry Society.

Herron, J. D., \& Greenbowe, T. (1986). What Can We Do About Sue: A Case Study of Competence. Journal of Chemical Education, 61, 185 $-199$.

Krulik, S. \& Rudrick, J. (1980). "Teaching Problem Solving to Preservice Teachers." Arithmetic Teacher, 29, $414-418$.

Kvale, St. (1996). Interviews. Thousand Oaks. Sage Publications.

Larkin, J. H. (1983). "The Role of Problem Representation in Physics." In D. Gentner and A. L. Stevens (Eds.), Mental models (pp. 75 - 98). Hillsdale, NJ: Lawrence Erlbanum Associates.

Mason, D. S., Shell, D. F., \& Crawley, F. E. (1997). "Differences in Problem Solving by Nonscience Majors in Introductory Chemistry on Paired Algorithmic - Conceptual Problems." Journal of Research in Science Teaching, 34(9), 905 - 923. 
Meija, J., \& Bisenieks, J. (2004). "Mathematical Charm in Chemistry Problems." Journal of Chemical Education, 81(7), 995 - 996.

Mestre, J. P., Dufresne, R. J., Gerace, W. J., Hardiman, P. T., \& Touger, J. S. (1993). "Promoting Skilled Problem-Solving Behaviour among Beginning Physics Students." Journal of Research in Science Teaching, 30(3), $303-317$.

Nakhleh, M. C. (1993). "Are Our Students Conceptual Thinkers or Algorithmic Problem Solvers?" Journal of Chemical Education, 70, $52-55$.

Nakhleh, M., \& Mitchell, R. (1993). "Concept Learning Versus Problem Solving." Journal of Chemical Education, 70, 190 - 192.

Newell, A., \& Simon, H. A. (1972). Human Problem Solving. Englewood Cliffs, NJ: Prentice - Hall.

Niaz, M. (1995). "Progressive Transitions from Algorithmic to Conceptual Understanding in Student Ability to Solve Chemistry Problems: A Lakatosian Interpretation." Science Education, 79, 19 - 36.

Niaz, M., \& Robinson, W. R. (1992). "Manipulation of Logical Structure of Chemistry Problems and Its Effect on Student Performance." Journal of Research in Science Teaching, 29, 211 - 226.

Novak, J. D. (2002). "Meaningful Learning: The Essential Factor for Conceptual Change in Limited or Inappropriate Propositional Hierarchies Leading to Empowerment of Learners." Science Education, 86 (4), 548 - 571.

Nurrenbern, S., \& Pickering, M. (1987). "Concept Learning Versus Problem Solving: Is There A Difference?" Journal of Chemical Education, 64, $508-510$.

Pickering, M. (1990). "Further Studies of Concept Learning Versus Problem Solving." Journal of Chemical Education, 67, 254 - 255.

Reid, N., \& Yang, M. J. (2002). "Open-Ended Problem Solving in School Chemistry: A Preliminary Investigation." International Journal of Science Education, 24 (12), 1313 - 1332.

Reif, F. (1983). "How Can Chemists Teach Problem Solving?" Journal of Chemical Education, 60, 948953.

Sawrey, B. A. (1990). "Concept Learning Versus Problem Solving: Revisited." Journal of Chemical Education, 67, 253 - 254.

Schoenfeld, A., \& Herrmann, D. J. (1982). "Problem Perception and Knowledge Structure in Expert and Novice Mathematical Problem Solvers." Journal of Experimental Psychology: Learning, Memory and Cognition, 8, $484-494$. 
Suit, J. P. (2001). "Pioneering Pedagogic Publications: Algorithms, Student Understanding, and Chemical Knowledge." Journal of Chemical Education, 78 (8), 1015 - 1016.

Wheatley, G. H. (1984). Problem Solving In School Mathematics (MEPS Technical Report No. 8401). West Lafayette, IN: Purdue University, School of Mathematics and Science Center.

Wiegand, D. \& Samberg, T. (2000). Student Solutions Manual to Accompany Chemistry - The Molecular Nature Of Matter And Change. (2nd ed.) New York: The McGraw-Hill Companies, Inc.

Zikovelis, V. \& Tsaparlis, G. (2006). Explicit Teaching of Problem Categorization and a Preliminary Study of Its Effect on Student Performance - The Case of Problems in Colligative Properties of Ideal Solutions. Chemistry Education Research and Practice, 7(2), $150-158$.

Zoller, U., \& Doris, Y. J. (2002). "Algorithmic, LOC and HOCS (Chemistry) Exam Questions: Performance and Attitudes of College Students." International Journal of Science Education, 24 (2), 185 203.

Zoller, U., Lubezky, A., Nakhleh, M. B., Tessier, B., \& Dori, Y. J. (1995). "Success on Algorithmic and LOCS Vs Conceptual Chemistry Exam Questions." Journal of Chemical Education, 72, 987 - 989.

Zoller, U. \& Tsaparlis, G. (1997). "Higher - and Lower - Order Cognitive Skills: The Case of Chemistry." Research in Science Education, 27, $117-130$. 
Result of Interview Study as basis for the Categorization Chemistry Students...

Table 1: Frequency distribution of students based on their performances on CHEMPACT

\begin{tabular}{|c|c|c|c|c|}
\hline \multirow[b]{2}{*}{ Group } & \multicolumn{3}{|c|}{ Frequency } & \multirow[b]{2}{*}{ Total } \\
\hline & $\begin{array}{l}\text { Algorithmic } \\
\text { Problem } \\
\text { Solvers }\end{array}$ & $\begin{array}{l}\text { Conceptual } \\
\text { Problem } \\
\text { Solvers }\end{array}$ & $\begin{array}{c}\text { Non- } \\
\text { Participants }\end{array}$ & \\
\hline School I & $18(51.4)^{*}$ & $8(22.9)$ & $9(25.7)$ & 35 \\
\hline School II & $17(42.5)$ & $13(32.5)$ & $10(25.0)$ & 40 \\
\hline School III & $20(52.6)$ & $13(34.2)$ & $5(13.2)$ & 38 \\
\hline School IV & $11(34.4)$ & $9(28.1)$ & $12(37.5)$ & 32 \\
\hline Overall total & 66 (45.5) & $43(29.7)$ & $36(24.8)$ & 145 \\
\hline
\end{tabular}

* Figures in brackets represent percentages 